\title{
Factors Affecting School Selection
}

\author{
Aimen Zahra Naqvi Dr.Itrat Batool Naqvi \\ Forman Christian College ( A Chartered University ) Lahore, Pakistan
}

\begin{abstract}
The following study investigated the factors that parents consider while selecting a school for their child. For this research two Schools having same basic traits e.g., well known, standard fee structure, bilingual mode of communication, healthy learning environment, and community services, selected in order to collect the data. A semi-structured questionnaire has been used as a tool to collect the data. In total data was collected from 340 respondents, using SPSS. The study was analyzed using chi square test of association, spearman rank correlation and factor analysis. The results showed that a total of 9 factor were extracted namely, school reputation, respondent practices, respondent information, travelling to school, teacher's behavior, fee structure and spoon feeding, behavior of custodian, teaching at home and selection of the school which parents should consider for surely while selecting a school.
\end{abstract}

Keywords: school selection, education, children

DOI: $10.7176 / \mathrm{JEP} / 12-32-08$

Publication date: November $30^{\text {th }} 2021$

\section{Introduction}

One of the primary focus in UDHR-Universal Declaration of Human Right is the 'the right to educate'. Even the MDGs and now the SDGs, both primarily focus on 'Education for All'. According to Mandela (1990):

"Education is the most powerful weapon which you can use to change the world"..

The era of $21^{\text {st }}$ century is the era of globalization, where education has a great significance and plays its vital role in making a great difference in a learner's life directly and the world at large. Therefore, choosing the right institution is very important step for children to be admitted to school, because schooling creates a routine and a healthy lifestyle.

Basic traits of the schools

Below are some basic traits and qualities of schools for the following research.

- A renowned institute

- Affordable fee structure

- The medium of communication

- Healthy learning environment

- Community services

- A renowned institute

The schools in this research are one of the most well-known schools of the current city. Also the institutes hold a strong academic history historical background that attracts the parents, when it comes for choosing a school for their child.

- Affordable fee structure

A fix and standard as well as minimum fee structure that fits to parent's pocket is offered in the schools.

- The medium of communication

It is strictly ordered to speak English language in class as well as with peers. Apart from that the students who lack at English language are encouraged to lean and speak English in extra classes. But an overall a bilingual mode of communication is being followed throughout the schools.

- Healthy learning environment

The benchmark is set to check that the children are tip top when it comes to uniform. However, a criterion is set to check that the child brings healthy homemade lunch, also they keep a proper check on student's hygiene that is checking nails and lices on monthly basis.

Moreover, there are different activities such as sports galas, annual plays, art and craft that enhance the children physical health and social moral values.

- Community services

The schools are working on the theme of community services. Charity and fund raising are being practiced in the school by conducting different activities; such as annual newspaper drive, annual fun fair for collecting money for donation and charity. However, in case of any sudden accidents (earth quakes, floods etc) donation, charity, food and clothing is collected to help the people in the hour of need. This is to foster equity, and encourage students to help others those who are in need. The schools have almost the similar qualities and are mostly preferred by the parents in the current city. 
The main objective of the study is to identify the significant factors that parents considered while selecting a particular school for their child.

\section{Literature Review}

This paper contends with the research of factors affecting the school choice The study highlighted several factors hence literature review's based on the study have been carried out to identify the factors affecting the school choice. Many studies put forth different opinions regarding the following topic. For instance, some researchers found out that, academic performance, school syllabus, school environment were the factors that influence the parents. Moreover, some other like, affordable cost of education. Safety and awareness, school reputation, administrative staff and parent's income level were also taken in consideration. The above mentioned factors are somehow related with each other. The brief discussion of the previous researchers is mentioned blow:

Mainda. (2001), discussed the factors that are influencing the school choice entitle "A study on selected factors influencing school choice among the seventh-day Adventist Population in southwest Michigan". The author used the multiple regression, Analysis of variance (ANOVA) techniques to carry out the analysis of the data. Mainda.(2001) reported that academic program, affordable cost of education, safety, and awareness are the main factors that affect the parental perception on the school choice.

According to the research work of Anemone. (2008), who had studied about "A descriptive study of the factors influencing Middle school choice in a Diverse Magnet School District in Northern New Jersey". The author has applied Analysis of Variance (ANOVA), the post Hoc, t-test, as well as mean scores and frequency statistics to examine the data using quantitative and qualitative approach. Anemone. (2008), study revealed that the quality of teacher staff was considered the major factor by the parents. And additional that is the overall reputation of school and administrative staff was also taken in consideration.

According to Hartsell.(2011), who worked on the "Factors affecting private school choice". The basic idea the researcher was to know other factors rather than academic purpose for then the selection of the private school. A self-administered mail questionnaire was designed to gather the data. The author used SPSS to apply one-way ANOVA and chi-square test to find out different factors. The study concluded that parents considered a positive climate and prepared their children for college life.

From the research of Yaacob et. al. (2015) who has studied about "An assessment of factors influencing parents' decision making when choosing a private school for their children: a case study of Selangor, Malaysia for sustainable human capital". The central idea of author was to analyze the parent's motivation in deciding a private school. Descriptive and inferential statistics has been applied to summarize the findings like the percentage and frequency of the variables as well as the mean scores. And by the end he ranked the following factors (income level, social background, distance and location, quality of teachers school performance, school environment and the school syllabus) on the basis of mean scores.

The research work of Thanerajah. (2017), who had studied about "Factors influencing parents on choosing international private school ahead of Government schools in Malaysia". The main focus of author was to find out factors that influence parents in selecting factors such as sexual orientation, age, training level, parents employment position, school syllabus, school offices and school execution. The data was analyzed using scores, percentages, mean, and standard deviation with the help of SPSS software. Also the techniques of Analysis of Variance (ANOVA) was applied to check the homogeneity amongst the variables, and multiple regression to determine the relationship between variables. The overall result showed that there was no correlation between the syllabus and school performance, also the school facilities was also not supported because there was no significant correlation.

\section{Methodology}

A semi structured questionnaire was designed to collect the required data. The survey contained liker scale questions and it was distributed in hard copies to the parents of the selected school A and B. The analysis was carried out using statistical package for the social sciences (SPSS). In total data was collected from 340 respondents, from school A and B, 170 each. 26 questions were asked.

The overall analysis was done by using three methods:

1. Univariate analysis

2. Bivariate analysis

3. Multivariate analysis

\section{Results and Discussion}

The data showed that out of 340 respondents 202 males and 138 females, with an average age of 46.5 years and majority were doing private jobs. The bivariate analysis was conducted by Spearman rank correlation, Chisquare test of association and Fisher exact test.

Interpretation of infrastructure and Co-curricular activities 
The variables, Infrastructure and co-curricular activities are highly correlated having test statistics 17.899 and Pvalue $(0.001)$. Both the variables are positivity correlated at $5 \%$ level of significance which means that if the infrastructure is good enough the co-curricular will enhance.

The infrastructure is also correlated with the following variables:

- Teachers qualification

- Strong foundation

In the same very pattern all the other variables can be described.

\subsection{Factor Analysis}

Factor analysis is, use to reduce the large amount of data into small different factors. Factor analysis is mostly used in Psychological and human behavior phenomena.

\subsection{KMO and Bartlett's test}

Table 4.2 KMO and Bartlett's test

\begin{tabular}{|l|l|}
\hline KMO & 0.621 \\
\hline Bartlett's test & 1409.587 \\
\hline Significance & 0.000 \\
\hline
\end{tabular}

KMO is a measure of sampling adequacy, it tests the amount of variation that can be explained by the factors within the data. In our study the KMO's value is 0.621 which is larger than the 0.5 said to be appropriate by Kaiser(1970). The Bartlett's test is significant (0.000), which shows that there exists sufficient number of correlation between the variables. So we can apply the factors analysis on this data set but if it is insignificant then it is recommended not to apply factor analysis.

\subsection{The total variance explained}

In the table the Eigen value along with the proportion of the variables explained by each of the 9 factors. As the formulation of the eigenvalue is bounded to Eigen value greater than 1. The 9 factor explained 58.300 percent of data variation. After the varmix rotation the extracted components are shown in the rotation sum of squared loading, here one point is important to mention that the percentage of variance, eigenvalues and cumulative percent of variance explained by all the components that have been changed after rotation.

Table 4.3 Total variance explained

\begin{tabular}{|c|c|c|c|c|c|c|c|c|c|}
\hline Component & \multicolumn{3}{|c|}{ Initial Eigenvalues } & \multicolumn{3}{|c|}{ Extraction SS Loading } & \multicolumn{3}{|c|}{ Rotation SS Loadings } \\
\hline & Total & $\begin{array}{l}\% \\
\text { variance }\end{array}$ & $\begin{array}{l}\text { Cumulative } \\
\%\end{array}$ & Total & $\begin{array}{l}\% \\
\text { variance }\end{array}$ & $\begin{array}{l}\text { Cumulative } \\
\%\end{array}$ & Total & $\begin{array}{l}\% \\
\text { variance }\end{array}$ & $\begin{array}{l}\text { Cumulative } \\
\%\end{array}$ \\
\hline 1 & 2.732 & 10.509 & 10.509 & 2.732 & 10.509 & 10.509 & 2.238 & 8.609 & 8.609 \\
\hline 2 & 2.341 & 9.003 & 19.512 & 2.341 & 9.003 & 19.512 & 1.958 & 7.531 & 16.140 \\
\hline 3 & 1.959 & 7.536 & 27.048 & 1.959 & 7.536 & 27.048 & 1.887 & 7.257 & 23.397 \\
\hline 4 & 1.853 & 7.126 & 34.174 & 1.853 & 7.126 & 34.174 & 1.723 & 6.628 & 30.025 \\
\hline 5 & 1.525 & 5.866 & 40.040 & 1.525 & 5.866 & 40.040 & 1.710 & 6.577 & 36.602 \\
\hline 6 & 1.271 & 4.889 & 44.929 & 1.271 & 4.889 & 44.929 & 1.690 & 6.499 & 43.101 \\
\hline 7 & 1.200 & 4.617 & 49.546 & 1.200 & 4.617 & 49.546 & 1.441 & 5.542 & 48.643 \\
\hline 8 & 1.175 & 4.519 & 54.065 & 1.175 & 4.519 & 54.065 & 1.303 & 5.013 & 53.656 \\
\hline 9 & 1.101 & 4.235 & 58.300 & 1.101 & 4.235 & 58.300 & 1.207 & 4.644 & 58.300 \\
\hline 10 & 0.946 & 3.640 & 61.940 & & & & & & \\
\hline 11 & 0.921 & 3.543 & 65.482 & & & & & & \\
\hline 12 & 0.913 & 3.512 & 68.995 & & & & & & \\
\hline 13 & 0.858 & 3.300 & 72.295 & & & & & & \\
\hline 14 & 0.785 & 3.019 & 75.314 & & & & & & \\
\hline 15 & 0.762 & 2.932 & 78.246 & & & & & & \\
\hline 16 & 0.750 & 2.886 & 81.132 & & & & & & \\
\hline 17 & 0.685 & 2.636 & 83.768 & & & & & & \\
\hline 18 & 0.597 & 2.295 & 86.063 & & & & & & \\
\hline 19 & 0.572 & 2.201 & 88.264 & & & & & & \\
\hline 20 & 0.548 & 2.108 & 90.372 & & & & & & \\
\hline 21 & 0.500 & .922 & 92.293 & & & & & & \\
\hline 22 & 0.441 & 1.696 & 93.989 & & & & & & \\
\hline 23 & 0.438 & 1.685 & 95.675 & & & & & & \\
\hline 24 & 0.407 & 1.566 & 97.2413 & & & & & & \\
\hline
\end{tabular}




\begin{tabular}{|l|l|l|l|l|l|l|l|l|l|}
\hline Component & \multicolumn{3}{|l|}{ Initial Eigenvalues } & \multicolumn{3}{l|}{ Extraction SS Loading } & \multicolumn{3}{|c|}{ Rotation SS Loadings } \\
\hline & Total & $\begin{array}{l}\% \\
\text { variance }\end{array}$ & $\begin{array}{l}\text { Cumulative } \\
\%\end{array}$ & Total & $\begin{array}{l}\% \\
\text { variance }\end{array}$ & $\begin{array}{l}\text { Cumulative } \\
\%\end{array}$ & Total & $\begin{array}{l}\% \\
\text { variance }\end{array}$ & $\begin{array}{l}\text { Cumulative } \\
\%\end{array}$ \\
\hline 25 & 0.377 & 1.449 & 98.690 & & & & & & \\
\hline 26 & 0.341 & 1.310 & 100.000 & & & & & & \\
\hline
\end{tabular}

\subsection{Scree plot}

The scree plot is the visual measure to pick our factors. And the general rule of thumb is to pick the factors before the elbow marked. Here in our case the elbow is made at tenth factor which is also complying total variance explained phenomenon.

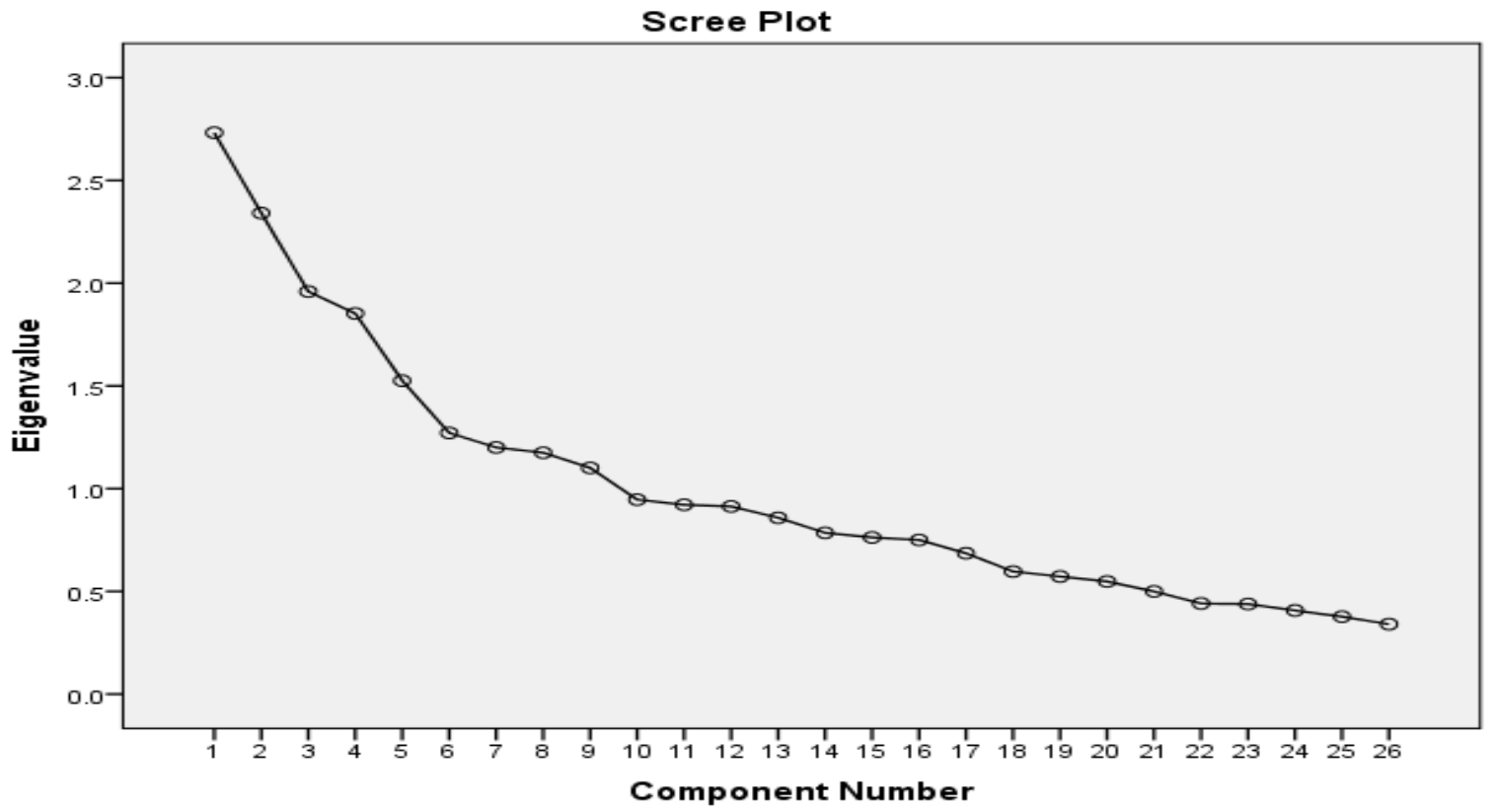

4.5 Extracted factors

Figure 4.4 Scree Plot

Table 4.5 Extracted factors

\begin{tabular}{|l|l|}
\hline Factor & Variable \\
\hline F1=School reputation & $\begin{array}{l}\text { Rate the school, Providing Strong foundation for future concern, } \\
\text { Co-curricular activates, Hygienic condition, Infrastructure, Teacher's } \\
\text { qualification. }\end{array}$ \\
\hline F2= Respondent practice & $\begin{array}{l}\text { Children need tuition, How many children do you have, Admission criteria, } \\
\text { Do you think fee matters }\end{array}$ \\
\hline F3= Respondent information & Profession, Age, Qualification of respondents. \\
\hline F4= Traveling to school & Drop your child at school, Distance, Gender \\
\hline F5=Teachers behavior & $\begin{array}{l}\text { Behavior of teachers, Medium of instruction, Came to know about the } \\
\text { school, Child treated active, }\end{array}$ \\
\hline $\begin{array}{l}\text { F6= Fee structure and no Spoon- } \\
\text { feeding }\end{array}$ & $\begin{array}{l}\text { Do you think Spoon feeding teaching is practiced, Satisfied with the fee } \\
\text { structure. }\end{array}$ \\
\hline F7=Behavior of custodian & Behavior of custodian \\
\hline F8=Teaching at home & Teaching at home \\
\hline F9=Selection of the school & Selection of the school \\
\hline
\end{tabular}

\section{Conclusion}

For this research two Schools having same basic traits e.g., well known, standard fee structure, bilingual mode of communication, healthy learning environment, and community services, selected in order to collect the data. A semi-structured questionnaire has been used as a tool to collect the data. In total data was collected from 340 respondents, 202 males and 138 females, with an average age of 46.5 year and majority were doing private jobs. Overall the results were significant, and the commonalties were all above 0.3 , however it was observed that 25 out of 26 items correlated at least 0.3 with at least one other item suggesting reasonable factorability (Table 4.4.7). Secondly, the Kaiser-Meyer-Olkin measure of sampling adequacy was 0.62 , above the commonly 
recommended value of 0.5 , and Bartlett's test of sphericity was also significant $(1409.58$, p-value $=0.000)$ finally the communalities were all above 0.3(Table 4.3.3) further confirming that each item shared some common variance with other items. Given these overall indicators, factor analysis was deemed to be suitable with all 26 questions. Hence the extracted nine factors are: School Reputation, respondent practices, respondent information, travelling to school, Teacher's behavior, fee structure and spoon feeding, behavior of custodian, teaching at home and quality education are the 9 extracted factors with initial Eigen values 2.732, 2.341, 1.959, $1.853,1.525,1.271,1.200,1.175,1.101$ respectively and explaining $58.300 \%$ variation.

\section{References}

1. Kasier, H. F. (1970). A second generation little jiffy. Psychometrika. 35.

2. Mandela, N. (1990). Speech, Madison Park High School, Boston.

3. Mainda, P. Omenge. (2001). A Study on Selected Factors Influencing School Choice Among the Seventhday Adventist Population In Southwest Michigan.https://digitalcommons.andrews.edu/cgi/viewcontent.cgi?article=1551\&context=dissertations Retrieved date 25,november, 2021

4. Anemone,A.(2008). A descriptive study of the factors influencing Middle school choice in a Diverse Magnet School District in Northern New https://scholarship.shu.edu/cgi/viewcontent.cgi?article=1078\&context=dissertations Retrieved date 20,November,2020

5. Hartsell,J.H.(2011).Factors affecting private school choice. https://aquila.usm.edu/dissertations/732/. Retrieved date, 09,May,2021.

6. Yaacob,N.A., Osman,M. M., and Bachok,S.( 2015). An assessment of factors influencing parents' decision making when choosing a private school for their children: a case of Selangor, Malayia: For sustainable human capital. Procedia Environmental Science 28.

7. Thanerajah, V. R., and Razilan, R, B.A.(2017). "Factors influencing parents on choosing international private schools ahead of government schools in Malaysia". International Journal of Accounting and Business Management.5(1) 